\title{
ANALYSIS OF FATAL TRAIN-PEDESTRIAN COLLISIONS IN METROPOLITAN CHICAGO 2004-2012
}

\author{
Ian Savage ${ }^{1}$ \\ Northwestern University
}

Published in Accident Analysis and Prevention, volume 86, pages 217-228, 2016.

\begin{abstract}
The paper analyzes spatial and temporal data on fatal train-pedestrian collisions in the Chicago metropolitan area between 2004 and 2012. In comparing different municipalities within the region, the density of grade crossings and stations is found to increase the frequency of unintentional deaths. However, unintentional deaths do not increase with train volume suggesting that pedestrians may exercise more care around busier lines. The distribution of apparent intentional deaths is less strongly related to the density of crossings and stations suggesting that those intending self-harm will seek out a point of access. Apparent intentional deaths are more prevalent on lines with frequent passenger trains, and in municipalities with higher incomes and lower population densities. While most of the apparent intentional deaths (about 70\%) are not associated with any copycat activities, the dataset contains possible clusters of intentional deaths that are proximate in both time and space. There was also a highlypublicized suicide that led to a 95\% increase in apparent intentional deaths throughout the region in the 18 weeks following the incident.
\end{abstract}

\section{Key Words}

Railroad - Safety - Pedestrians - Chicago - Suicide

\section{Highlights}

- Apparent intentional deaths are $50 \%$ of total pedestrian deaths

- Apparent intentional deaths are concentrated on lines with passenger service

- Unintentional deaths are related to the number of public access points

- Copycat behavior may explain about 1 in 6 of the intentional deaths

\footnotetext{
${ }^{1}$ Department of Economics, Northwestern University, 2001 Sheridan Road, Evanston IL 60208, USA. Phone: +1-847-491-8241, e-mail ipsavage@northwestern.edu.
} 


\title{
ANALYSIS OF FATAL TRAIN-PEDESTRIAN COLLISIONS IN METROPOLITAN CHICAGO 2004-2012
}

\author{
Ian Savage \\ Northwestern University
}

\section{INTRODUCTION}

Approximately 800 non-motorized members of the general public die each year on the railroads in the United States. ${ }^{2}$ These are primarily pedestrians, but also include wheel-chair users, pedal bicyclists and horse riders. As shown in table 1, they represent about four out of every five railroad-related deaths (79.8\%) during the period 2012 to 2014. This proportion is not only large, but has also increased during the past 35 years.

Table 1: Annual Railroad Fatalities in United States (Average of 2012, 2013 and 2014)

\begin{tabular}{|c|c|c|c|}
\hline \multicolumn{2}{|c|}{$\begin{array}{c}\text { Primarily Non-Motorized Members of the } \\
\text { General Public }\end{array}$} & \multicolumn{2}{|l|}{ Other Fatalities } \\
\hline $\begin{array}{l}\text { On the right-of-way at places other } \\
\text { than grade crossings }{ }^{3}\end{array}$ & 441 & $\begin{array}{l}\text { Motorized highway users at grade } \\
\text { crossings }\end{array}$ & 163 \\
\hline Confirmed intentional deaths ${ }^{4}$ & 274 & Employees and contractors & 19 \\
\hline $\begin{array}{l}\text { Pedestrians and non-motorized } \\
\text { highway users at grade crossings }\end{array}$ & 79 & $\begin{array}{l}\text { Other persons lawfully on the } \\
\text { railroad, such as delivery drivers }\end{array}$ & 13 \\
\hline & & Passengers on trains & 5 \\
\hline & & Bystander not on railroad property & 1 \\
\hline Total & 794 & Total & 201 \\
\hline
\end{tabular}

Source: Federal Railroad Administration

Annual non-motorized deaths have not changed much in recent decades whereas the counts in other categories of death on the railroads have declined. The total number of persons who died at places along the right-of-way other than grade crossings (commonly referred to as “trespassers") has been reasonably consistent within the range of 400 to 500 a year for decades. The same is true for the number of non-motorized fatalities at grade crossings that have fluctuated in the range of 60 to 100 a year. A time trend for intentional deaths (suicides) is not available because prior to June 2011 railroads were not required to report suicidal acts to the federal government. In contrast there has been a considerable reduction in employee fatalities. The total number of employees is only half of what it was in 1976, and the fatality risk per employee hour has fallen by 70\% (Savage, 2013). Even more astonishing is the decline in the number of motor vehicle occupant fatalities at grade crossings from 1,016 in 1976 to about 160 in recent years despite highway traffic doubling in volume.

\footnotetext{
${ }^{2}$ The railroads considered are freight, intercity passenger, regional commuter and switching railroads regulated by the Federal Railroad Administration. Incidents on urban rapid transit subway and light rail systems are not included.

${ }^{3}$ A small number of persons in this category are occupants of motor vehicles that leave an adjacent highway and end up on the tracks, and some snowmobile and all-terrain vehicle riders.

4 There are a handful of intentional deaths involving motor vehicles stopped on grade crossings.
} 
These divergent trends have had their effect on public policy. One of the most pressing safety issues facing the railroad industry in the 1970s was grade crossing collisions. In the early1970s the number of non-motorized and vehicular fatalities at grade crossings exceeded trespassing fatalities elsewhere on the railroad by a ratio of three to one. Programs were put into place that reduced the risk (Mok and Savage, 2005; Savage, 2006). By 1997 the number of trespasser fatalities exceeded the number killed in collisions at grade crossings for the first time since 1941. The trend continued and today the number of crossing fatalities is only about half of the number of trespasser fatalities. Consequently the railroad industry, both in the United States and elsewhere in the world, has increasingly turned its attention to understanding and mitigating unintentional pedestrian deaths and suicides (Botha, Neighbour and Kauer, 2014; Fitzpatrick et al., 2015; Gabree, Chase, Doucette and Coplen, 2014; Harrison and DaSilva, 2013; Havârneanu, Burkhardt and Paran, 2015; RESTRAIL Consortium, 2014; and a working group known as the Global Railway Alliance for Suicide Prevention (GRASP)).

The purpose of this paper is to assist efforts to mitigate these risks by analyzing a dataset of 338 fatalities from collisions between pedestrians and other non-motorized members of the general public with railroad trains in metropolitan Chicago between 2004 and 2012. This dataset has the advantage relative to national data that intentional acts are included (intentional acts were not reportable to the federal government prior to June 2011, and even after that time detailed data on individual incidents are not made publicly available). The analysis looks at the type of activity that preceded the death, demographics of the decedent, the time of the incident, the characteristics of the railroad service, and the land use in the vicinity of the incident location. Statistical analyses are also used to discern the extent to which there is any contagion whereby an intentional death spurs others to imitate the act.

\section{LITERATURE REVIEW}

\subsection{Literature on Unintentional Deaths}

Savage (2007) undertook a time series analysis of unintentional fatalities (at locations other than grade crossings) in the United States from 1947 to 2003 . He found that while the total number of such fatalities may not have changed in recent decades, the per-capita risk has declined as the population has increased. Part of the explanation is that the railroad network has shrunk and new housing and workplace developments have occurred in places that are far away from the nearest railroad track. However, the resurgence in rail traffic since the 1980s has seen average train volumes increase on the parts of the network that remained open. There are also demographic factors at work. Trespassers tend to be in their 20s and 30s, and as the baby boom generation has aged a smaller proportion of the population is in that age group.

A particularly insightful literature involves the analysis of postmortem reports from coroners and medical examiners. The Centers for Disease Control and Prevention (CDC) conducted two such studies in the 1990s in North Carolina (Pelletier, 1997) and Georgia (CDC, 1999). Subsequently the Federal Railroad Administration (FRA) commissioned a report that matched up 61\% of the trespassing fatalities (unintentional deaths not at grade crossings) in the FRA national database for 2002, 2003 and 2004 with coroners' reports (George, 2008). The work was updated with 2005-2010 data in FRA (2013). At the risk of generalizing, these 
analyses concluded that about two-thirds of the trespasser casualties were single adult males in their 20s and 30s under the influence of alcohol.

This problem is not confined to the United States. Lobb (2006) presents an international overview of the relatively small literature that existed at the time on the nature of trespass and potential countermeasures. More recent work includes work in Finland looking at the characteristics of decedents (Silla and Luoma, 2012) and an evaluation of the effectiveness of specific countermeasures (Silla and Luoma, 2011). The former study found that decedents in accidental collisions were primarily in the 20 -29 age group, $77 \%$ were male and $70 \%$ were intoxicated. In the latter study fencing and landscaping barriers were found to be more effective that just posting warning signs, but at a much higher cost. The estimated ratio of benefits to costs was 4.7:1 for fencing and landscaping and 5.4:1 for just signage. Work in Australia has used surveys of pedestrian users of grade crossings to determine why people engage in risk behaviors (Freeman, et al., 2013; Lloyd’s Rail Register 2007).

\subsection{Literature on Intentional Deaths}

In contrast to the somewhat sparse literature on unintentional deaths, suicides have engendered a comparatively large literature. Much of the literature deals with deaths on subway systems. Review articles include Mishara (2007), Ratnayake, Links and Eynan (2007) and Krysinska and De Leo (2008).

In theory, suicides should not have been reported to the FRA or included in the trespassing statistics prior to June 2011. However, the FRA (2013) found that between 28\% and $36 \%$ of the deaths in the FRA trespasser database were either ultimately determined to be suicides by a coroner, or the coroner's report contained language strongly suggesting suicide as the motive. Martino, Gabree and Chase (2013) provide some descriptive statistics on 696 deaths in the FRA trespasser database between 2005 and 2010 that were determined to be suicides. Then Martino, Doucette, Chase and Gabree (2013) examined 55 of these suicides in detail by conducted a "psychological autopsy" that involved interviewing friends and relatives of the deceased. Sung, Shults and Bhat (2015) from the CDC recently analyzed coroners' reports on 479 train suicides that occurred in 16 states between 2005 and 2011. They found that decedents in train suicides were typically younger than was the case for suicides in general, and were primarily male and single. Two-fifths of decedents tested positive for alcohol, and a quarter of female decedents tested positive for anti-depressant drugs.

The problem of rail suicides appears to be worse in Europe than it is in the United States. Dense rail passenger networks and restrictions on gun ownership result in trains being chosen as the method in a higher proportion of total suicides. Silla and Luoma (2012) found that suicide was the explanation for $85 \%$ of fatal train-pedestrian collisions. Suicide decedents were primarily in the 20-39 age group and 70\% were male. Half of these decedents were intoxicated, and two-fifths had received prior mental health treatment.

Another strand of the literature has looked at the geographical location of incidents to try to determine whether specific land uses affect the frequency of incidents. Botha, Elmasu and Leitzell (2010) looked at 200 intentional deaths that occurred along a 77-mile stretch of railroad 
near San Francisco, California between 1992 and 2010. In part they found that suicides occurred more frequently in older residential neighborhoods where the railroad right-of-way was a more integral part of the community. Andriessen and Krysinska (2012) analyzed 482 suicides on the Belgian mainline (which is to say non-rapid transit) railways between 2003 and 2007 and identified 34 "hot spots" that accounted for 35\% of all of the suicides. Characteristics of these locations were a lack of fencing, the presence of a nearby grade crossing, and in half of the locations the presence of a nearby mental health institution. Uittenbogaard and Ceccato (2015) analyzed the locations of suicides on the Stockholm subway system and found that there were higher rates of suicide at stations located in poorer suburbs and in areas with a higher incidence of drug-related crime.

In the suicide literature there is a discussion as to whether suicides cluster together due to copycat action. A frequently-cited study found that suicides on the Vienna, Austria subway increased during a period when the media provided extensive coverage (Sonneck, Etzersdorfer and Nagel-Kuess, 1994). Recent papers found that intentional deaths on German mainline railroads were $44 \%$ higher than would be expected in the two-month period following a highly publicized incident in December 2006 (Kunrath, Baumert and Ladwig, 2011) and 81\% higher in the 51-days following the death of a well-known soccer player in November 2009 (Ladwig, Kunrath, Lukaschek and Baumert, 2012).

\section{DATA}

\subsection{Data Sources}

The data in this paper deals with fatalities resulting from collisions between nonmotorized members of the general public and on-track rail equipment in six counties (Cook, DuPage, Kane, Lake, McHenry and Will) in Northeastern Illinois from 2004 to 2012. The study area comprises the City of Chicago, its suburbs, exurbs, and some semi-rural areas. The area is home to 8.3 million people, and has a dense and busy freight, intercity passenger and commuter rail network. The data excludes the physically separated rail rapid transit system operated by the Chicago Transit Authority.

The data were collected by the Illinois Commerce Commission (ICC), which is the state agency tasked with oversight of the railroad industry, and also coordinates the distribution of federal and state funds for upgrading highway-rail grade crossings. The ICC is alerted to incidents by reports submitted to the FRA, the Federal National Response Center, and the Illinois Emergency Management Agency, and by monitoring the news media. The ICC then follows up to obtain additional documentation from reports prepared by attending municipal and/or railroad police departments, and local coroners and medical examiners. The database contains information on the time, location, train, circumstances of the incident, and some basic demographics of the decedent. The database does not contain the results of any toxicology tests that may have been conducted by a coroner.

This dataset has two unusual and attractive features when a comparison is made to the FRA database. The first is that it includes intentional deaths. Prior to June 2011 such deaths were not reportable to the FRA, and the FRA does not publicly release detailed information on 
individual suicides that have occurred since 2011. The second major difference is that it appears that many unintentional fatalities that the ICC became aware of are not found in the FRA database. A quarter of the unintentional deaths that do not occur at a crossing or station (28 out of 107) in this dataset were not reported to the FRA as either a fatality or an injury. For unintentional deaths at crossings or station platforms, the proportion was smaller (3 out of 70 or $4 \%$ ). The ICC reports that much of the discrepancy occurred in the period prior to 2011 when incidents thought be intentional deaths were not reportable (albeit that the ICC eventually concluded these incidents were likely unintentional).

The dataset contains 338 fatalities that occurred in 334 separate incidents. There are only four two-fatality events (albeit that another pedestrian may have suffered non-fatal injuries or escaped uninjured in the same incident). Nearly all of the fatalities are pedestrians (327 of 338), with the remainder pedal cyclists. Therefore the term "pedestrians" will be used interchangeably with "non-motorized persons." There were no on-train fatalities in any of these incidents. There is no evidence of any time trend. Annual fatalities fluctuate in the range of 29 to 46 per year.

\subsection{Classification of Types of Fatalities}

The fatalities are classified into three groups: apparent intentional deaths (suicides), unintentional deaths occurring at crossings and stations, and unintentional deaths occurring elsewhere along the railroad.

Apparent intentional deaths comprise about half of the total (161 deaths, $47 \%$ of the total). The ICC classifies a death as a suicide in a more permissive manner than does the FRA. The FRA classification is based on a determination by a coroner, medical examiner or a nonrailroad police officer. The ICC also considers the content of police and coroners reports and applies a version of the "Ovenstone criteria" that is used by the railway industry in Great Britain. ${ }^{5}$ Consequently the terms "apparent intentional deaths" or "apparent suicides" will be used when referring to the Illinois data. Of the 161 apparent intentional deaths, 27\% were located at stations and their immediately adjacent highway crossings, 32\% were at freestanding crossings, and the remaining $41 \%$ were on plain track.

The remaining, unintentional deaths are then separated into two groups based on the incident location. The first of these groups are those occurring at crossings and stations. These are locations where pedestrians have legal access to railroad property. Crossings and stations are considered together because the flat terrain and the predominant use of low-level platforms means that the access to and between platforms is usually accomplished by highway grade crossings adjacent to the platforms and walkways in the middle of the station. This group accounts for 70 deaths or $21 \%$ of the total. Twenty of the deaths occurred at stations (people stepping off station platforms or using pedestrian walkways between platforms), 21 at highway

${ }^{5}$ The Ovenstone criteria is used in Britain to categorize "suspected suicides" when a coroner cannot make a conclusive determination of the decedent's motivation. It is derived from the work of Ovenstone (1973). Details of how the criteria are applied in Britain can be found in Appendix C of Gabree, Chase, Doucette and Coplen (2014). Reynders, Scheerder and van Audenhove (2011) discuss how national published suicide data may underreport the occurrence of suicides on the railways of 15 countries in Europe. 
crossings located immediately adjacent to a station, and the other 29 at freestanding highway crossings.

The second group of unintentional deaths comprises those that are not at crossings or stations. These fatalities occurred at locations where pedestrians clearly do not have legal access. This group comprises 107 deaths or $32 \%$ of the total.

\section{SUMMARY STATISTICS}

\subsection{Comparison with Non-Pedestrian Rail Deaths in Metropolitan Chicago}

Table 2 compares the pedestrian deaths with all other fatalities that occurred on the railroads in the six-county area in the same time period and reported to the FRA. Pedestrian fatalities represent $84 \%$ of total railroad fatalities. Not only do pedestrian deaths represent the vast majority of rail deaths in metropolitan Chicago, they also occur quite frequently with a pedestrian death every ten days on average.

Table 2: Railroad Fatalities in Metropolitan Chicago 2004-2012

\begin{tabular}{|l|r|l|r|}
\hline \multicolumn{2}{|c|}{$\begin{array}{c}\text { Non-Motorized Members } \\
\text { of the General Public }\end{array}$} & \multicolumn{2}{c|}{ Other Fatalities } \\
\hline Apparent intentional deaths & 161 & Motor vehicle occupants / riders & 39 \\
\hline $\begin{array}{l}\text { Unintentional deaths at places other } \\
\text { than grade crossings or stations }\end{array}$ & 107 & Vehicular intentional deaths & 2 \\
\hline $\begin{array}{l}\text { Unintentional deaths at grade } \\
\text { crossings and stations }\end{array}$ & 70 & Railroad employees & 6 \\
\hline & & Railroad contractors & 4 \\
\cline { 3 - 4 } & & Passengers on trains & 5 \\
\cline { 3 - 4 } & $\mathbf{3 3 8}$ & Total & $\mathbf{6 4}$ \\
\hline Total
\end{tabular}

Sources: Illinois Commerce Commission and Federal Railroad Administration

\subsection{Comparison of Chicago with National Data}

There are some notable differences when the distribution of fatality types in metropolitan Chicago from 2004 to 2012 (table 2) is compared with a similar table of national data for 2012 to 2014 (table 1). At a national level confirmed intentional deaths are $30 \%$ of the non-motorized total whereas in Chicago the proportion represented by apparent intentional deaths is $47 \%{ }^{6}$ While this may be due in part to the wider classification of a suicide by the ICC, other evidence points to the greater prevalence of trains as a method of suicide in Chicago. A study of coroners' reports from 2005 to 2008 for four of the six countries in this study plus one county elsewhere in Illinois (Peoria County) found that $4.1 \%$ of all suicides were by train (Children's Memorial Hospital of Chicago Research Center, 2011). This would include suicides on the Chicago rapid

\footnotetext{
${ }^{6}$ The Chicago region has a completed suicide rate by all methods that is below the average for the entire United States. By worldwide standards the suicide rate in the United States is in the middle of the rankings according to the World Health Organization.
} 
transit rail system. This is considerably higher than the proportion in the nation as a whole where suicides by train (both on railroads and rapid transit rail) are less than $1 \%$ of total suicides.

While high by national standards, the $4.1 \%$ ratio is not inconsistent with that seen in other countries with a dense rail network (Krysinska and De Leo, 2008). In explaining the difference between the Chicago region and the nation as a whole, it is notable that slightly more than $50 \%$ of all suicides nationally involve firearms, whereas the Chicago study found that firearms were involved in 33\% of suicides. The State of Illinois had, at the time covered by this analysis, one of the most restrictive gun ownership and use laws in the nation. Martino, Doucette, Chase and Gabree (2013) found by interviewing friends and relatives of decedents that proximity to rail tracks and a lack of access to firearms were likely contributing factors to decedents choosing trains as a method of suicide.

Another difference is that non-motorized crossing and station users form a higher proportion of non-motorized fatalities (21\%) in Chicago, whereas nationally $10 \%$ of nonmotorized fatalities occur at crossings, including pedestrian crossings at stations. The Chicago region has a well-patronized commuter rail service, and many of the suburban towns are centered on the railroad station, so there is considerable foot traffic across the railroad. As a consequence unintentional deaths away from crossings and stations are only 32\% of the non-motorized total in Chicago but comprise $60 \%$ of the non-motorized deaths nationally.

\section{DEMOGRAPHIC ANALYSIS}

\subsection{Analysis by Gender}

The gender of the decedent is recorded in $90 \%$ of cases. For those cases in which gender is known, males are $57 \%$ of the unintentional deaths at crossings and stations, $80 \%$ of the unintentional deaths elsewhere on the right-of-way, and $73 \%$ of the apparent intentional deaths. The FRA does not have a field on their report form for gender, so there is no definitive national comparison. But the Chicago data is consistent with the subset of the national database that was matched up with coroners' reports. FRA (2013) found that 82\% of the trespassing decedents were male. Martino, Gabree and Chase (2013) found that $72 \%$ of suicide decedents were male. A similar proportion (76\%) was found by Sung, Shults and Bhat (2015).

There is some evidence that suicide by train is a somewhat more prevalent method of suicide for females in Northeastern Illinois. Females are $27.2 \%$ of apparent intentional deaths in this study whereas they represent $21.8 \%$ of decedents by all methods of suicide in the six-county area. ${ }^{7}$ This difference is just statistically different at the $10 \%$ level using a two-tailed test.

\subsection{Analysis by Age}

Data on age were reported for $84 \%$ of the decedents. Table 3 shows the annual risk per million in the Chicago area by category and age group. These rates are based on the assumption

\footnotetext{
${ }^{7}$ The source of the total suicides data is the interactive database (iQuery) of the State of Illinois Department of Public Health. This database contains information for 2004 through 2008 and 2012. Data for 2009, 2010 and 2011 are not available.
} 
that the ages of decedents whose age was not reported follow the same age distribution as those whose age is known. In parentheses are 95\% two-tailed confidence intervals based on the assumption that the observed number of deaths in a particular cell is an unbiased estimator of the mean of a Poisson distribution.

Table 3: Annual Fatality Risk per Million by Age Group (with 95\% Poisson confidence intervals in parentheses)

\begin{tabular}{|c|c|c|c|c|}
\hline Age Group & $\begin{array}{c}\text { Unintentional } \\
\text { Deaths at } \\
\text { Crossings \& } \\
\text { Stations }\end{array}$ & $\begin{array}{c}\text { Unintentional } \\
\text { Deaths at Other } \\
\text { Locations }\end{array}$ & $\begin{array}{c}\text { Apparent } \\
\text { Intentional } \\
\text { Deaths }\end{array}$ & Total \\
\hline $0-9$ & $0.1(0.0-0.3)$ & $0.1(0.0-0.4)$ & - & $\mathbf{0 . 2}(\mathbf{0 . 0}-\mathbf{0 . 5})$ \\
\hline $10-19$ & $0.8(0.3-1.3)$ & $1.1(0.5-1.7)$ & $3.9 *(2.4-5.4)$ & $\mathbf{4 . 6}(\mathbf{3 . 1}-5.8)$ \\
\hline $20-29$ & $1.5(0.8-2.2)$ & $1.5(0.7-2.4)$ & $2.7(1.6-3.7)$ & $\mathbf{5 . 7}(\mathbf{4 . 2}-7.3)$ \\
\hline $30-39$ & $1.1(0.5-1.7)$ & $2.4(1.4-3.3)$ & $2.2(1.3-3.1)$ & $\mathbf{5 . 7}(\mathbf{4 . 2}-7.1)$ \\
\hline $40-49$ & $1.2(0.6-1.8)$ & $2.7(1.6-3.7)$ & $3.2(2.0-4.3)$ & $\mathbf{7 . 0}(\mathbf{5 . 3}-8.6)$ \\
\hline $50-59$ & $0.9(0.3-1.4)$ & $1.5(0.8-2.3)$ & $2.6(1.5-3.6)$ & $\mathbf{4 . 9}(\mathbf{3 . 4}-6.2)$ \\
\hline $60-69$ & $0.7(0.2-1.2)$ & $0.8(0.2-1.4)$ & $2.5(1.2-3.8)$ & $\mathbf{4 . 0}(\mathbf{2 . 3}-5.5)$ \\
\hline $70-79$ & $1.2(0.3-2.2)$ & $1.1(0.0-2.2)$ & $1.4(0.4-2.5)$ & $3.8(1.7-5.9)$ \\
\hline $80+$ & $1.3(0.0-2.6)$ & 0 & 0 & $\mathbf{1 . 3}(\mathbf{0 . 0}-2.9)$ \\
\hline Overall & $\mathbf{0 . 9}(\mathbf{0 . 7}-1.1)$ & $\mathbf{1 . 4}(\mathbf{1 . 2}-1.7)$ & $\mathbf{2 . 2}(\mathbf{1 . 8}-2.5) \#$ & $\mathbf{4 . 5}(\mathbf{4 . 0}-5.0)$ \\
\hline
\end{tabular}

* The apparent intentional death rate for this age group is based on the population in age range 13-19

\# The overall suicide fatality risk per million for those aged 13 and older is 2.6 with a $95 \%$ confidence interval of 2.2 to 3.0

Perhaps surprisingly it shows that people in their 40s are at the greatest overall risk. The 40-49 age group in this study has a high risk in all categories, with a particularly high risk of apparent suicide. This is consistent with the Children's Memorial Hospital of Chicago Research Center (2011) study that found that those in the 45-54 age group had the highest rate of completed suicides by all methods.

The groups with the next highest levels of risk are those in their 20s and 30s. This is somewhat consistent with the CDC studies from the 1990s and FRA studies that found that people in their 20s and 30s had elevated risks of unintentional deaths not at crossings ("trespassing"). The current results vary somewhat from the earlier studies in that unintentional deaths not at crossings or stations peak for people in their 30s and 40s, while those in their 20s have an elevated risk at crossings and stations.

Those aged 60 and older generally face lower risks. The rate of unintentional deaths not at crossings and stations declines after the age of 60, and the rate of intentional death after the age of 70. There does appear to be some increase in risk for those above the age of 70 when using stations or highway crossings. Perhaps this is due to slower reaction times, diminished hearing and sight, and a slower pace which lengthens crossing times.

Unintentional deaths involving persons aged younger than 20 are surprising few (especially considering the popular image of "kids playing on the tracks"), and deaths of those younger than ten are rare. However, the intentional death rate for those in the 13 to 19 age group 
is the highest of all age groups, and is $50 \%$ higher than the average rate for all person aged 13 and older.

Table 4: Distribution of Suicide Decedents by Age Group for those Aged 15 or Older

\begin{tabular}{|c|c|c|}
\hline Age Group & $\begin{array}{c}\text { All Methods of Confirmed } \\
\text { Suicides } \\
\text { Northeast Illinois (2005-2008) }\end{array}$ & $\begin{array}{c}\text { Apparent Intentional Deaths } \\
\text { on Railroads } \\
\text { Chicago (2004-2012) }\end{array}$ \\
\hline $15-24$ & $12.8 \%$ & $24.8 \%+$ \\
\hline $25-34$ & $14.4 \%$ & $13.2 \%$ \\
\hline $35-44$ & $19.7 \%$ & $21.7 \%$ \\
\hline $45-54$ & $22.0 \%$ & $19.4 \%$ \\
\hline $55-64$ & $16.7 \%$ & $14.7 \%$ \\
\hline $65-74$ & $14.4 \%$ & $6.2 \%-$ \\
\hline
\end{tabular}

- indicates proportion is statistically significantly lower at the $99 \%$ level based on a null hypothesis that fatalities follow the distribution for suicides by all methods

+ indicates proportion is statistically significantly higher at the $99 \%$ level based on a null hypothesis that fatalities follow the distribution for suicides by all methods

Table 4 provides further insights into intentional death rates by age. It shows the distribution of decedents by age (for those aged 15 or older). The middle column shows the data on all suicides for the five Illinois counties from 2005 to 2008 in the Children's Memorial Hospital of Chicago Research Center (2011) study. ${ }^{8}$ The right-hand column shows the data from this study. The two distributions are similar for those aged between 25 and 64, however train is a significantly more favored method of suicide for those aged 15 to 24, and a much less favored method for those aged 65 and older. For these two age groups the differences between the distributions are highly statistically significant at the $1 \%$ level.

\section{TEMPORAL ANALYSIS}

\subsection{Analysis by Time of Year}

The distribution of fatalities across the year, classified by the seasons, is shown in table 5 . A two-tailed hypothesis test was conducted at the 95\% level based on the null hypothesis that fatalities in each category are uniformly distributed across seasons. Both apparent intentional deaths and unintentional deaths not at crossings or stations are statistically significantly less likely to happen in the cold winter months of December through February when harsh conditions limit outdoor activity. Intentional deaths peak in the spring.

Interestingly $27 \%$ of unintentional crossings and stations deaths occurred in the month of June, for reasons that are not readily explainable. One might have imagined that the risk would be higher in winter as people wear headgear that might restricting their field of vision, and visibility is limited by more hours of darkness and falling snow. However, this does not appear to be the case.

\footnotetext{
${ }^{8}$ The rates per 100,000 in each age group were used in combination with the known age distribution for the five counties in the 2010 Census to calculate the number of number of suicides in each age category. The Illinois Department of Health dataset could not be used for this purpose as the counts of suicides in many age categories were withheld for the smaller counties to preserve individual confidentiality.
} 
Table 5: Distribution of Fatalities by Month of the Year

\begin{tabular}{|c|c|c|c|}
\hline Months & $\begin{array}{c}\text { Unintentional Deaths } \\
\text { at Crossings \& } \\
\text { Stations }\end{array}$ & $\begin{array}{c}\text { Unintentional Deaths } \\
\text { at Other Locations }\end{array}$ & $\begin{array}{c}\text { Apparent } \\
\text { Intentional Deaths }\end{array}$ \\
\hline December-February & $23 \%$ & $13 \%-$ & $17 \%-$ \\
\hline March-May & $14 \%-$ & $30 \%$ & $34 \%+$ \\
\hline June-August & $37 \%+$ & $28 \%$ & $25 \%$ \\
\hline September-November & $26 \%$ & $29 \%$ & $25 \%$ \\
\hline
\end{tabular}

- indicates proportion is statistically significantly lower than average at the $95 \%$ level based on a null hypothesis that fatalities are distributed uniformly across seasons

+ indicates proportion is statistically significantly higher than average at the $95 \%$ level based on a null hypothesis that fatalities are distributed uniformly across seasons

\subsection{Analysis by Day of Week}

The distribution of fatalities by day of the week is shown in table 6. A two-tailed hypothesis test was conducted at the 95\% level based on the null hypothesis that fatalities in each category are uniformly distributed across the week. There is a surprising consistency across the week. Compared with national data and previous research which indicates higher risks on Friday and Saturday evenings (Savage, 2007), unintentional deaths away from crossings and stations do not seem to increase on the weekend (albeit, of course, that there are fewer commuter trains in service on the weekend). There is some evidence of an increase in apparent intentional deaths on Fridays.

Table 6: Distribution of Fatalities by Day of Week

\begin{tabular}{|c|c|c|c|}
\hline Day of Week & $\begin{array}{c}\text { Unintentional Deaths } \\
\text { at Crossings \& } \\
\text { Stations }\end{array}$ & $\begin{array}{c}\text { Unintentional Deaths } \\
\text { at Other Locations }\end{array}$ & $\begin{array}{c}\text { Apparent } \\
\text { Intentional Deaths }\end{array}$ \\
\hline Monday & $16 \%$ & $7 \%-$ & $13 \%$ \\
\hline Tuesday & $14 \%$ & $17 \%$ & $12 \%$ \\
\hline Wednesday & $10 \%$ & $20 \%$ & $16 \%$ \\
\hline Thursday & $21 \%$ & $12 \%$ & $20 \%+$ \\
\hline Friday & $20 \%$ & $15 \%$ & $11 \%$ \\
\hline Saturday & $10 \%$ & $15 \%$ & $16 \%$ \\
\hline Sunday & $9 \%$ & $15 \%$ & $12 \%$ \\
\hline
\end{tabular}

- indicates proportion is statistically significantly lower than average at the $95 \%$ level based on a null hypothesis that fatalities are distributed uniformly across the week

+ indicates proportion is statistically significantly higher than average at the 95\% level based on a null hypothesis that fatalities are distributed uniformly across the week

\subsection{Analysis by Time of Day}

The distribution of fatalities by time of day, listed by hour and also summarized into three-hour windows, is shown in table 7. A two-tailed hypothesis test was conducted at the 95\% level based on the null hypothesis that fatalities in each category are uniformly distributed across the day. Not surprisingly, 56\% of the unintentional fatalities at crossings and stations occur in 
the prime commuting hours of 7am-9am and 3pm-7pm when there are a large number of pedestrians and trains about. Unintentional deaths at other locations appear to be generally equally spread across all hours of day and night. Apparent intentional deaths are also distributed across the day, but with a significantly higher frequency during the peak afternoon commuting hours between $5 \mathrm{pm}$ and $7 \mathrm{pm}$.

Table 7: Distribution of Fatalities by Time of Day

\begin{tabular}{|c|c|c|c|c|c|c|}
\hline Time of Day & \multicolumn{2}{|c|}{$\begin{array}{l}\text { Unintentional Deaths at } \\
\text { Crossings \& Stations }\end{array}$} & \multicolumn{2}{|c|}{$\begin{array}{l}\text { Unintentional Deaths at } \\
\text { Other Locations }\end{array}$} & \multicolumn{2}{|c|}{$\begin{array}{c}\text { Apparent } \\
\text { Intentional Deaths }\end{array}$} \\
\hline 01:00-01:59 & $1.4 \%$ & \multirow{3}{*}{$4.3 \%-$} & $2.8 \%$ & \multirow{3}{*}{$6.5 \%$} & $6.2 \%$ & \multirow{3}{*}{$10.6 \%$} \\
\hline $02: 00-02: 59$ & $0.0 \%$ & & $2.8 \%$ & & $2.5 \%$ & \\
\hline 03:00-03:59 & $2.9 \%$ & & $0.9 \%$ & & $1.9 \%$ & \\
\hline 04:00-04:59 & $7.1 \%$ & \multirow{3}{*}{$12.9 \%$} & $4.7 \%$ & \multirow{3}{*}{$13.1 \%$} & $1.2 \%$ & \multirow{3}{*}{$8.7 \%$} \\
\hline 05:00-05:59 & $2.9 \%$ & & $1.9 \%$ & & $2.5 \%$ & \\
\hline 06:00-06:59 & $2.9 \%$ & & $6.5 \%$ & & $5.0 \%$ & \\
\hline 07:00-07:59 & $12.9 \%+$ & \multirow{3}{*}{$21.4 \%+$} & $3.7 \%$ & \multirow{3}{*}{$10.3 \%$} & $6.2 \%$ & \multirow{3}{*}{$13.1 \%$} \\
\hline 08:00-08:59 & $7.1 \%$ & & $4.7 \%$ & & $3.7 \%$ & \\
\hline 09:00-09:59 & $1.4 \%$ & & $1.9 \%$ & & $3.1 \%$ & \\
\hline 10:00-10:59 & $0.0 \%$ & \multirow{3}{*}{$1.4 \%-$} & $7.5 \%$ & \multirow{3}{*}{$15.0 \%$} & $3.7 \%$ & \multirow{3}{*}{$13.0 \%$} \\
\hline $11: 00-11: 59$ & $1.4 \%$ & & $1.9 \%$ & & $3.7 \%$ & \\
\hline $12: 00-12: 59$ & $0.0 \%$ & & $5.6 \%$ & & $5.6 \%$ & \\
\hline $13: 00-13: 59$ & $4.3 \%$ & \multirow{3}{*}{$15.7 \%$} & $0.9 \%$ & \multirow{3}{*}{$8.4 \%$} & $4.3 \%$ & \multirow{3}{*}{$11.8 \%$} \\
\hline $14: 00-14: 59$ & $2.9 \%$ & & $5.6 \%$ & & $2.5 \%$ & \\
\hline $15: 00-15: 59$ & $8.6 \%$ & & $1.9 \%$ & & $5.0 \%$ & \\
\hline $16: 00-16: 59$ & $5.7 \%$ & \multirow{3}{*}{$27.1 \%+$} & $3.7 \%$ & \multirow{3}{*}{$15.9 \%$} & $5.0 \%$ & \multirow{3}{*}{$19.9 \%+$} \\
\hline $17: 00-17: 59$ & $8.6 \%$ & & $9.3 \%+$ & & $7.5 \%+$ & \\
\hline 18:00-18:59 & $12.9 \%+$ & & $2.8 \%$ & & $7.5 \%+$ & \\
\hline 19:00-19:59 & $7.1 \%$ & \multirow{3}{*}{$11.4 \%$} & $1.9 \%$ & \multirow{3}{*}{$15.9 \%$} & $3.1 \%$ & \multirow{3}{*}{$11.2 \%$} \\
\hline $20: 00-20: 59$ & $4.3 \%$ & & $5.6 \%$ & & $3.7 \%$ & \\
\hline $21: 00-21: 59$ & $0.0 \%$ & & $8.4 \%+$ & & $4.3 \%$ & \\
\hline $22: 00-22: 59$ & $1.4 \%$ & \multirow{3}{*}{$2.9 \%$} & $0.9 \%$ & \multirow{3}{*}{$15.0 \%$} & $3.1 \%$ & \multirow{3}{*}{$11.8 \%$} \\
\hline $23: 00-23: 59$ & $1.4 \%$ & & $4.7 \%$ & & $5.0 \%$ & \\
\hline $00: 00-00: 59$ & $2.9 \%$ & & $9.3 \%+$ & & $3.7 \%$ & \\
\hline
\end{tabular}

- indicates proportion is statistically significantly lower than average at the $95 \%$ level based on a null hypothesis that fatalities are distributed uniformly across the day

+ indicates proportion is statistically significantly higher than average at the $95 \%$ level based on a null hypothesis that fatalities are distributed uniformly across the day

\section{DETERMINING POTENTIAL CLUSTERS OF APPARENT INTENTIONAL DEATHS}

The prior literature on intentional deaths has devoted considerable attention to the extent to which there is "contagion" whereby some suicides - especially well-publicized ones engender copycat incidents. This section of the paper uses statistical tools to gain insights into whether some localized clusters in time and space within the dataset are the result of contagion as opposed to being an artifact of a random Poisson process. The latter would produce some 
incidents that occur in proximity to each other without a presumption that the subsequent death or deaths are in imitation of the first death.

\subsection{Effect of a Highly-Publicized Intentional Death}

There was a widely-publicized rail suicide in Chicago on May 7, 2010. The decedent was the longtime head of the commuter rail agency. He was on his way to a board meeting of the agency at which he was likely to be dismissed due to financial improprieties that had already been widely discussed in the media. Table 8 shows the count of apparent intentional deaths for the 18 weeks prior to and after May 7 for each of the nine years in the dataset (the death that occurred on May 7 is not included in this table).

Table 8: Count of Apparent Intentional Deaths in 18 Weeks Prior to and After May 7

\begin{tabular}{|c|c|c|}
\hline Year & January 1 to May 6 & May 8 to September 10 \\
\hline 2004 & 4 & 8 \\
\hline 2005 & 6 & 5 \\
\hline 2006 & 8 & 5 \\
\hline 2007 & 4 & 6 \\
\hline 2008 & 6 & 8 \\
\hline 2009 & 11 & 2 \\
\hline 2010 & 5 & 13 \\
\hline 2011 & 5 & 4 \\
\hline 2012 & 8 & 9 \\
\hline
\end{tabular}

The mean number of apparent intentional deaths in the May to September period is 6.67, whereas the actual number in 2010 was 13 . The Poisson probability that there would be 13 or more apparent intentional deaths in the period due to pure chance is 0.0192 , or approximately once in every 50 years. Therefore it is reasonable to conclude that the extensive public interest in the incident did lead to additional apparent intentional deaths by train that year.

\subsection{Potential Local Clusters of Intentional Deaths}

The suicide that has just been discussed was publicized throughout the Chicago region, and the subsequent additional apparent intentional deaths occurred in all parts of the region. In general the region-wide media outlets in Chicago are very restrained in reporting on rail deaths when it becomes known that suicide was the likely explanation. However, news of a suicide may spread through localized social circles and social and public media.

The first step was to filter the dataset to identify potential candidates for localized clusters. The filtering criterion was that there had to be two or more apparent intentional deaths occurring in the same municipality, or an adjacent municipality along the same rail line, with less than four calendar months between incidents. ${ }^{9}$ This is a quite strict filter. The annual per capita rate of apparent intentional deaths in suburban municipalities that have rail service is 3.46 per

\footnotetext{
${ }^{9}$ There were no cases where there were multiple apparent intentional death decedents in any one incident. Railroad intentional deaths in the City of Chicago are rare, and there were no occasions when two apparent intentional deaths occurred in the same area of the City within a four-month period.
} 
million. A typical suburban municipality in Chicago has a population of 22,000 which implies that even a single apparent intentional death in a municipality in a given year is a low probability event, and two or more apparent intentional deaths in a municipality and its adjacent neighbors in a short period of time would be very unusual.

TABLE 9: POTENTIAL CLUSTERS OF APPARENT INTENTIONAL DEATHS

\begin{tabular}{|c|c|c|c|c|c|c|}
\hline $\begin{array}{c}\text { Potential } \\
\text { Cluster }\end{array}$ & $\begin{array}{l}\text { Initiating } \\
\text { and } \\
\text { Subsequent } \\
\text { Fatalities } \\
\text { (X) }\end{array}$ & $\begin{array}{c}\text { Duration } \\
\text { (Days) }\end{array}$ & $\begin{array}{l}\text { Population } \\
\text { (rounded) }\end{array}$ & $\begin{array}{c}\text { Probability } \\
\text { that } \\
\text { Subsequent } \\
\text { Fatalities } \geq \\
\text { X-1 }\end{array}$ & $\begin{array}{l}\text { Expected } \\
\text { Period } \\
\text { between } \\
\text { Intentional } \\
\text { Deaths } \\
\text { (Years) }\end{array}$ & $\begin{array}{c}\text { Expected } \\
\text { Period } \\
\text { between } \\
\text { Same or } \\
\text { Worse } \\
\text { Outcome } \\
\text { (Years) }\end{array}$ \\
\hline 1 & 2 & 105 & 51,400 & 0.0522 & 5.4 & 103 \\
\hline 2 & 2 & 58 & 70,600 & 0.0695 & 2.2 & 32 \\
\hline 3 & 2 & 87 & 22,800 & 0.0308 & 7.6 & 247 \\
\hline 4 & 2 & 68 & 10,300 & 0.0076 & 24.5 & 3,237 \\
\hline 5 & 2 & 33 & 18,300 & 0.0094 & 9.6 & 1,014 \\
\hline 6 & 2 & 64 & 52,900 & 0.0578 & 2.9 & 51 \\
\hline 7 & 2 & 73 & 22,400 & 0.0283 & 7.0 & 245 \\
\hline 8 & 3 & 55 & 143,700 & 0.0014 & 2.8 & 2,037 \\
\hline 9 & 2 & 16 & 141,900 & 0.0299 & 1.4 & 48 \\
\hline 10 & 2 & 28 & 28,600 & 0.0054 & 14.2 & 2,622 \\
\hline 11 & 2 & 64 & 65,100 & 0.0707 & 2.4 & 34 \\
\hline 12 & 2 & 21 & 40,700 & 0.0142 & 4.0 & 283 \\
\hline 13 & 2 & 38 & 10,300 & 0.0042 & 24.5 & 5,782 \\
\hline 14 & 3 & 97 & 65,100 & 0.0057 & 2.4 & 418 \\
\hline 15 & 2 & 16 & 27,100 & 0.0029 & 14.9 & 5,094 \\
\hline 16 & 2 & 34 & 23,700 & 0.0054 & 17.1 & 3,134 \\
\hline 17 & 5 & 159 & 141,900 & 0.0003 & 1.4 & 5,281 \\
\hline 18 & 3 & 77 & 19,400 & 0.0003 & 9.0 & 33,463 \\
\hline 19 & 4 & 56 & 92,500 & 0.0001 & 1.7 & 14,269 \\
\hline 20 & 2 & 21 & 59,000 & 0.0205 & 2.8 & 135 \\
\hline
\end{tabular}

Seventy percent (113 of 161) of apparent intentional deaths were "single events" and not part of a potential cluster. However, there were twenty potential clusters. One potential cluster comprised five fatalities, one had four fatalities, three had three fatalities, and fifteen had two fatalities. We do not know whether or not a particular decedent imitated a previous suicidal act, but we can use a statistical analysis to estimate the probability that a particular cluster would have occurred by pure chance. The analysis of the twenty potential clusters is shown in table 9. For each of the potential clusters the table shows the number of fatalities (including the initiating one), the duration, and the population of the relevant municipality or municipalities. The potential clusters are displayed in chronological order, but the municipality name(s) and the specific dates are not included to prevent publicizing these locations. 
The analysis will presume that the initiating fatality is purely random. The Poisson distribution is then used to calculate the probability of subsequent fatalities within the time duration of the potential cluster. Presuming that subsequent fatalities occur randomly, the expected number of subsequent fatalities is calculated by multiplying the known daily rate of apparent rail intentional deaths per capita in rail-served municipalities in the county in which the municipality is located, ${ }^{10}$ the duration of the cluster in days from the first to the last fatality, and the population of the municipality or municipalities.

The fifth column shows the Poisson probability of the observed number of subsequent fatalities, or a worse outcome, occurring by pure chance. For example, potential cluster 8 has two subsequent fatalities in 55 days. The probability of two or more subsequent fatalities in 55 days or less is 0.0014 or about 1 in 700 . Of course, it should be remembered that an initiating random intentional death is also a very rare event. Based on the county average rate for railserved municipalities, the expected time between intentional deaths in years is shown in the sixth column. The final column calculates how often, due to pure chance, an initiating intentional death would occur followed by subsequent death(s) in the observed duration period that is the same or worse than that observed. For example, in potential cluster 8 the same or worse (more fatalities, shorter duration) outcome would occur by pure chance once every 2,000 years.

For 14 of the 20 potential clusters (representing 22 of the 28 subsequent fatalities) the probability that the same or a worse outcome would occur by pure chance is less likely than once in every 200 years. Ten of these (representing 17 of the 28 subsequent fatalities) would occur less frequently than once in every thousand years. Of course, it should be remembered that it is possible that even a once in every 3,000 year event may occur due to pure chance in any given year in a certain municipality.

Potential clusters 2 and 11 are interesting. They are the least unlikely to occur of all of the potential clusters. Each is expected to occur once every thirty or so years. However, they overlap geographically, and there are two other clusters (numbers 14 and 19) in the same geographic area. The three adjacent municipalities that comprise these four potential clusters recorded 15 apparent intentional deaths between 2004 and 2012 (11 in potential clusters and 4 in single events). With a combined population of 92,000, the annual apparent intentional death rate in these three municipalities is five times the overall rate for all of the rail-served suburban municipalities in the metropolitan Chicago region.

Within these twenty potential clusters there is evidence to support the contention that young people are particularly susceptible to copycat behavior. Eleven of the 25 (44\%) subsequent decedents (four female, seven male) for whom their age is known were 21 or younger, whereas $23 \%$ of all suicide decedents are in this age group. In five of these 11 cases the initial decedent in the potential cluster was also aged 21 or younger.

\footnotetext{
${ }^{10}$ Intentional death rates vary considerably by county within the study area with the outer suburban counties (DuPage and Lake) having much higher rates than the exurban counties or the inner suburban areas (Cook County outside of the City of Chicago). This is discussed later in the paper.
} 


\section{ANALYSIS BY TYPE OF RAIL LINE AND TRAIN TYPE}

Table 10 presents data on the distribution of fatalities by the type of rail line and the type of train involved. This table cannot be interpreted as a fatality rate because information on train miles on different routes and by different types of trains is not available at a region-wide level. However, information on train volume and type is available when the risk in individual municipalities is analyzed later in the paper. Despite the lack of exposure data, some general observations can be made. The first is that more than $80 \%$ of the fatalities occur on routes where there is commuter rail service and $60 \%$ of the fatalities involve commuter trains. In particular, apparent intentional deaths appear to be more attracted to commuter passenger trains $(67 \%$ versus $60 \%$ of the unintentional deaths at crossings and stations, and $48 \%$ unintentional deaths elsewhere along the right-of-way) perhaps because commuter trains run to a published schedule.

Table 10: Distribution of Fatalities by Category of Train Line and Train Type

\begin{tabular}{|l|c|c|c|c|}
\hline Train Line Type / Train Type & $\begin{array}{c}\text { Unintentional } \\
\text { Deaths at } \\
\text { Crossings \& } \\
\text { Stations }\end{array}$ & $\begin{array}{c}\text { Unintentional } \\
\text { Deaths at } \\
\text { Other } \\
\text { Locations }\end{array}$ & $\begin{array}{c}\text { Apparent } \\
\text { Intentional } \\
\text { Deaths }\end{array}$ & Total \\
\hline Commuter Railroad Routes \\
\hline \multicolumn{5}{|l|}{} \\
\hline Commuter Train & $60 \%$ & $48 \%-$ & $67 \%+$ & $\mathbf{5 9 \%}$ \\
\hline Inter-City (Amtrak) Train & $11 \%$ & $8 \%$ & $4 \%$ & $\mathbf{7 \%}$ \\
\hline Freight Train & $13 \%$ & $17 \%$ & $17 \%$ & $\mathbf{1 6 \%}$ \\
\hline Sub-Total & $84 \%$ & $73 \%-$ & $88 \%$ & $\mathbf{8 2 \%}$ \\
\hline Non-Commuter Railroad Routes & $3 \%$ & $5 \%$ & $1 \%$ & $\mathbf{2 \%}$ \\
\hline Inter-City (Amtrak) Train & $13 \%$ & $22 \%+$ & $12 \%$ & $\mathbf{1 5 \%}$ \\
\hline Freight Train & $16 \%$ & $27 \%+$ & $12 \%$ & $\mathbf{1 8 \%}$ \\
\hline Sub-Total
\end{tabular}

- indicates proportion is statistically significantly lower than average at the $95 \%$ level based on a null hypothesis that fatalities in this category are distributed the same as total pedestrian fatalities

+ indicates proportion is statistically significantly higher than average at the $95 \%$ level based on a null hypothesis that fatalities in this category are distributed the same as total pedestrian fatalities

The second general observation is that $27 \%$ of unintentional deaths not at crossings or stations occur on non-commuter rail routes, compared with $16 \%$ of unintentional crossings and stations fatalities and $12 \%$ of apparent intentional deaths. This suggests that the inherently irregular scheduling of freight trains poses more of a risk to those trespassing on the right-of-way who are caught unawares by an unexpected train.

\section{SPATIAL ANALYSIS BY SUBURBAN MUNICIPALITY}

Most of the risk occurs in suburban municipalities and not within the City of Chicago. The City of Chicago has $30 \%$ of the population of the metropolitan area but only $20 \%$ of the pedestrian fatalities. The primary reason is that the City passed a series of ordinances between 1892 and 1930 that required railroads to grade separate their main lines from street level. The Chicago suburbs are composed of 270 municipalities of which 216 have railroad lines passing through them. The rail-served suburban municipalities range in size from 200 residents to 200,000 residents, but most are quite small. The average population is 22,000, and the median is 
15,000. The large number of suburban municipalities provides the opportunity for a statistical analysis because there is considerable variation in the fatality experience, the land use and the characteristics of rail service.

\subsection{Data}

Table 11 provides descriptive statistics for each of the variables that will be used in the analysis. The first three lines of the table represent the three dependent variables that will be used. These are the total count of fatalities from 2004 to 2012 that occur within the municipal boundaries for the three categories of non-motorized persons. Because most municipalities are small the modal value for each of these counts is zero, and the mean number of fatalities in all three categories combined is 1.2.

Table 11: Descriptive Statistics on 216 Suburban Rail-Served Municipalities

\begin{tabular}{|l|c|c|c|}
\hline & Minimum & Mean & Maximum \\
\hline $\begin{array}{l}\text { Unintentional deaths at crossings and stations } \\
2004-12\end{array}$ & 0 & 0.23 & 5 \\
\hline $\begin{array}{l}\text { Unintentional deaths not at crossings or stations } \\
\text { 2004-12 }\end{array}$ & 0 & 0.30 & 4 \\
\hline Apparent intentional deaths 2004-12 & 0 & 0.68 & 8 \\
\hline Population - 2010 census & 228 & 21,869 & 197,889 \\
\hline Public crossings and stations per square mile & 0 & 1.22 & 9.83 \\
\hline Daily trains & 2 & 68 & 233 \\
\hline Proportion of freight trains to total trains & 0.04 & 0.56 & 1.00 \\
\hline Maximum number of tracks & 1 & 2.16 & 6 \\
\hline Maximum line speed - miles per hour & 10 & 63 & 79 \\
\hline Population per square mile - 2010 census & 86 & 3,281 & 14,509 \\
\hline Median household income - 2010 census & $\$ 22,049$ & $\$ 76,629$ & $\$ 247,000$ \\
\hline
\end{tabular}

The extent of rail service in each municipality is measured by a variable that combines together the number of lines that traverse the municipality, the length of traverse, and most importantly whether the lines go through areas where roads intersect the rail lines, and if they do whether there is grade separation. The measure is the total number of public access points, measured by the sum of the public highway and pedestrian crossings and the number of passenger stations, per square mile. In 21 municipalities there are no stations and no crossings (indicating total grade separation or no intersecting highways or footpaths). On average there are 1.2 public access points per square mile. Seventeen municipalities have three or more access points per square mile with a maximum of 9.8 per square mile.

The volume of rail service is measured by the number of trains passing though the municipality each day. The data were obtained by filings from the railroads to the FRA as part of the inventory of highway-rail grade crossings, and are available on the FRA's website. If more than one railroad line passes through a municipality, this measure is the sum of the trains on each route. In the event that there are no grade crossings on a particular line within the municipality, the train count is derived from data on the most proximate crossing on that line. On average there are 70 trains a day indicating that the Chicago region is a busy hub for rail service. 
The nature of rail service is represented by three variables. The first is the proportion of the daily trains that are freight trains. These data are obtained from the FRA crossing inventory database, supplemented by commuter rail and Amtrak timetables. The second and third variables measure the number of tracks and the line speed. These are also from the FRA crossing inventory. When more than one line passes through a municipality, the variables represent the line with the most number of tracks, and the line with the highest speed.

The final two variables are characteristics of the municipality: the population density which would indicate land use, and the median household income. Both were obtained from the 2010 United States census. There is considerable variation in both, and there is a negative correlation between them with a correlation coefficient of -0.34 .

\subsection{Analytical Technique}

The regression technique used is the negative binomial regression with the count of fatalities as the dependent variable, population as the exposure (offset) variable, and most of the other explanatory variables expressed in logarithms. The negative binomial regression is a more generalized version of the Poisson regression. It assumes that the mean, E(Y), and variance, $\operatorname{Var}(\mathrm{Y})$, of the count of casualties for a group of municipalities with identical values of the explanatory variables have the following relationship:

$$
\operatorname{Var}(\mathrm{Y})=\mathrm{E}(\mathrm{Y})+\alpha \mathrm{E}(\mathrm{Y})^{2}
$$

The negative binomial equation can be usefully visualized as having the form:

$$
\text { count of fatalities }=\text { population } * \exp \left(\mathrm{a}+\sum \mathrm{b}_{\mathrm{i}} \ln \left(\mathrm{X}_{\mathrm{i}}\right)\right)+\varepsilon
$$

or

$$
\text { count of casualties/population }=\exp \left(\mathrm{a}+\sum \mathrm{b}_{\mathrm{i}} \ln \left(\mathrm{X}_{\mathrm{i}}\right)\right)+\varepsilon
$$

where $\mathrm{X}_{\mathrm{i}}$ is the set of explanatory variables other than population. This particular functional form means that because all but one of the non-population explanatory variables is expressed in logarithms, their coefficients can be interpreted as elasticities.

\subsection{Regression Results}

The regression results are shown in Table 12. The regressions have alpha values significantly larger than zero at the $1 \%$ level for apparent intentional deaths and for unintentional deaths not at crossings and stations, and at the $10 \%$ level for unintentional deaths at crossings and stations, thereby rejecting the Poisson model. As the estimated values of $\alpha$ are positive, the data are referred to as overdispersed. 
Table 12: Negative Binomial Regression Results

\begin{tabular}{|c|c|c|c|c|c|c|}
\hline \multirow[t]{2}{*}{$\begin{array}{l}\text { Dependent Variable. Count of } \\
\text { fatalities 2004-12 }\end{array}$} & \multicolumn{2}{|c|}{$\begin{array}{l}\text { Unintentional } \\
\text { Deaths at } \\
\text { Crossings \& } \\
\text { Stations }\end{array}$} & \multicolumn{2}{|c|}{$\begin{array}{l}\text { Unintentional } \\
\text { Deaths at Other } \\
\text { Locations }\end{array}$} & \multicolumn{2}{|c|}{$\begin{array}{c}\text { Apparent } \\
\text { Intentional Deaths }\end{array}$} \\
\hline & Coefficient & $\mathrm{t}$ & Coefficient & $\mathrm{t}$ & Coefficient & $\mathrm{t}$ \\
\hline Constant & -19.9459 & 2.24 & -15.2497 & 1.78 & -23.1304 & 3.79 \\
\hline $\begin{array}{l}\text { Ln of population (exposure } \\
\text { variable) }\end{array}$ & 1.0000 & - & 1.0000 & - & 1.0000 & - \\
\hline $\begin{array}{l}\text { Public crossings and stations } \\
\text { per square mile }\end{array}$ & 0.4119 & 3.38 & & 2.92 & 0.1588 & 1.85 \\
\hline Ln of daily trains & -0.01 & 0.04 & & 1.04 & 0.5952 & 2.30 \\
\hline $\begin{array}{l}\text { Ln of proportion of freight } \\
\text { trains }\end{array}$ & -0.1087 & 0.51 & -0.0224 & 0.10 & -0.2584 & 1.96 \\
\hline $\begin{array}{l}\text { Ln of maximum number of } \\
\text { tracks }\end{array}$ & 0.8228 & 1.35 & & 0.13 & -0.0533 & 0.13 \\
\hline Ln of maximum line speed & 0.7708 & 0.70 & 1.9283 & 1.64 & 0.9010 & 1.06 \\
\hline $\begin{array}{l}\text { Ln of population per square } \\
\text { mile }\end{array}$ & -0.1583 & 0.47 & -0.3618 & 1.17 & -0.4346 & 2.11 \\
\hline Ln of median household income & 0.4771 & 0.83 & -0.2705 & 0.46 & 0.8500 & 2.23 \\
\hline Alph & 0.9019 & 1.76 & 1.7753 & 2.61 & 0.5871 & 2.82 \\
\hline Pseudo $\mathrm{R}^{2}$ & 0.0845 & & 0.0703 & & 0.112 & \\
\hline Observations & 216 & & 216 & & 216 & \\
\hline
\end{tabular}

In general, the pseudo $\mathrm{R}^{2}$ statistics are quite poor at 0.07 for unintentional deaths not at crossings or stations, 0.085 for unintentional deaths at crossings and stations, and 0.1125 for apparent intentional deaths. The pseudo $\mathrm{R}^{2}$ is a measure, using the estimated log-likelihoods, of the explanatory power of the full regression compared with a regression with just a constant term and the offset variable (population) as the explanatory variables. The low pseudo $\mathrm{R}^{2}$ would support a hypothesis that, after allowing for the size of the population in each municipality, the occurrence of pedestrian fatalities is quite random. To some extent this is not unexpected as the suburban dataset contains 269 fatalities (50 unintentional crossings and stations fatalities, 73 unintentional fatalities elsewhere on the right-of-way and 146 apparent intentional deaths) and 216 potential municipalities that these fatalities could occur in. However, there are some factors that explain the higher risk of fatalities in some municipalities.

\subsection{Effect of the Extent of Rail Service}

Of course one would expect that the extent of the rail network in a municipality and its grade separation will have a major effect on the number of fatalities. This variable could not be expressed in logarithms as some municipalities have no public access points to the rail network, and the logarithm of zero is undefined. The relationship between the explanatory variables in a negative binomial regression is inherently multiplicative. For example in the unintentional deaths at crossings and stations equation the coefficient is 0.4119 . The effect of access density on the predicted fatality count is to multiply the prediction of the other variables by the natural exponential function of 0.4119 of the density of public access. When there are no public 
crossings or stations the value of the exponential function is 1.0, implying that the variable has no effect on the risk.

The estimated coefficients in the unintentional deaths at crossings and stations equation are almost identical to those in the equation for intentional deaths elsewhere on the right-of-way. Therefore, these two types of unintentional deaths will be discussed together. A municipality that has a public access density of 0.41 per square mile, which is at the lower quartile of the dataset, would have a count that is $18 \%$ higher than an otherwise similar municipality with no public access. In the median municipality where the access density is 0.78 per square mile the predicted count is 38\% higher than municipalities with no public access. At the upper quartile with 1.44 public access points per square mile the predicted count is $81 \%$ higher than municipalities with no public access. Because of the functional form, the predicted counts rise quite rapidly for those few municipalities with very high public access densities. The result certainly shows that grade separation is an effective, if costly, way to reduce not only fatalities that might occur at crossings and stations, but also unintentional deaths at other places along the right of way.

In contrast the estimated coefficient of the access density variable on apparent intentional deaths is much smaller. While it is statistically significant at the $10 \%$ level, it is not at the $5 \%$ level. The effect of this smaller coefficient is that the predicted count in a municipality at the upper quartile is only $26 \%$ higher than in a municipality with no public access. It is clear that suicidal persons seek out points of access, and do not seem to be greatly deterred by a lower density of public access points.

\subsection{Effect of the Volume and Nature of the Rail Service}

In the two unintentional death regressions, only one of the rail-service variables is statistically related to the fatality count. That is the train speed variable in the unintentional deaths not at crossings and stations regression. While only significant at the $10 \%$ level, the magnitude of the elasticity is large at 1.9 indicating that fatalities increase twice as fast as any increase in train speed. This is perhaps not surprising as faster trains leave those on the tracks with less time to move off to the side. The essentially zero coefficient on the freight train proportion variable indicates that such trespassers are equally susceptible to both fast freight and passenger trains. The insignificant coefficient for the number of tracks is somewhat surprising, as one would have imagined that three-track main lines are more risky to people using crossings or walking on the tracks than single or double track lines.

Surprisingly, there is no statistically-significant relationship between train volume and unintentional deaths. Indeed in the case of deaths at crossings and stations the estimated coefficient is close to zero. Perhaps there are conflicting forces at work. While an increased number of trains should increase the chance of a collision with a pedestrian, the higher train volume may encourage pedestrians to take more care. This would be consistent with the general theory of risk compensation (Hedlund, 2000) and with interviews of crossing users in Northeastern Illinois (Metaxatos and Sriraj, 2013).

For apparent intentional deaths, there is a statistically-significant positive relationship with train volume. However, the estimated elasticity is 0.5 indicating the increase in fatalities 
increases less than proportionately with train volume. While the number of tracks and the line speed are not statistically related to the fatality count, the proportion of freight trains is negatively related. That is to say apparent intentional deaths are more likely on lines where passenger trains are present. This is consistent with the analysis of the location of apparent intentional deaths versus other types of fatalities shown in table 10 . This would also be consistent with the hypothesis that those seeking deliberate self-harm are attracted to lines on which the trains run frequently and to a published schedule.

\subsection{Effect of Municipality Characteristics}

In the unintentional deaths regressions there are no statistically-significant relationships between population density or median household income and per capita fatality rates. In contrast for apparent intentional deaths there are strong statistical findings that per capita fatality rates decrease with population density (with an elasticity of -0.43) and increase with median household income (with an elasticity of 0.85). This explains why the outer suburban countries have the highest suicide by train rates. The reader is cautioned that the data represent the municipality in which the fatality occurs. The decedent may reside in another municipality, and the decedent's own household income is not known.

\subsection{The Effectiveness of Operation Lifesaver}

Analyses were undertaken to try to determine whether the public information efforts of “Operation Lifesaver” led to a reduced number of fatalities. Data were available on the number of audience members in each municipality in each year who attended an Operation Lifesaver event or activity. Placing an attendance rate into the previous regressions had poor results with no relationship being found between activities and the counts of unintentional deaths in a municipality. A strongly significant positive relationship was found with the number of intentional deaths, which is surprising as Operation Lifesaver expressly does not engage in suicide prevention activities.

Of course, there is a problem of endogeneity in that presumably Operation Lifesaver will try to focus its resources on the places with the highest risk. To attempt to correct for this, the time period was split into two (2004-2007 and 2008-2012), and an attempt was made to see whether a high level of activity in the earlier period led to a lower than expected count of fatalities in the later period. Unfortunately, the number of fatalities in each category in each municipality in each of the time periods was so small so that nearly all changes were from zero fatalities to one fatality or vice-versa. It is impossible to untangle any effects of Operation Lifesaver from the random patterns inherent in a Poisson process.

\section{DISCUSSION AND POLICY IMPLICATIONS}

Pedestrian fatalities constitute the overwhelming majority (84\%) of all deaths on the railroads in metropolitan Chicago. On average there is one such fatality every ten days. At both a local and national level, pedestrian fatalities appear to be stubbornly resistant to action to reduce their occurrence. This in contrast to other risks, such as collisions with motor vehicles at grade crossings and employee injuries, both of which have decreased in recent decades. 
So what can the present research add to the discussion on effective strategies to tackle this problem? One notable conclusion from the Chicago data is that the highest risks are to middle-aged people in their 40s. There tends to be a popular conception that the problems of pedestrians on the railroad are "teenage suicide" or "kids playing on the tracks." It is certainly true that 15-24 year olds do have an elevated suicide risk and are more likely to select suicide by train over other methods of suicide. But the rate of suicide again peaks in the middle-aged years, before declining rapidly for those aged 65 and above. Quite surprisingly the risk of unintentional death is much higher for those in their 30s and 40s than it is for teenagers and children. This might suggest that the traditional high school and senior center venues for Operation Lifesaver presentations may be a misallocation of resources. Channels of communication to middle-aged people may be more effecting at targeting those most at most risk.

While the decedents are primarily male, the problem is not exclusively confined to men. While females are only $20 \%$ of the decedents in unintentional deaths not at crossings and stations, the proportion rises to $27 \%$ of intentional deaths, and $43 \%$ of unintentional deaths at crossings and stations. Indeed there is some statistical support to suggest that females represent a higher proportion of completed suicides by train than they do for completed suicides by all methods. So some thought might be given to whether there needs to be specific publicity materials and public service announcements that might be targeted towards females, rather than having these materials developed by males for males.

Unintentional deaths are found, not surprisingly, to be strongly related to the density of public access points to the right of way. Consequently, grade separation is effective in reducing fatalities but at a great expense. Interestingly unintentional fatalities do not increase with train volume suggesting that pedestrians may exercise more care around busier lines. Consequently it might seem that frequent train traffic is, in itself, a sufficient warning sign on the busiest routes. The problem areas would seem to be on lines where trains are infrequent and crossing users and trespassers are caught out by an unexpected train.

Some of the earlier literature on unintentional deaths away from crossings ("trespassing”) has given the impression that this is a problem that is concentrated in the late evening hours, especially on the weekends. This is not the case in this study. Such fatalities occur at all times of day and days of the week. They are less frequent in the winter months when Chicago's severe winter weather discourages outdoor activity.

The Chicago data uses a version of the British "Ovenstone criteria" to identify both confirmed and suspected intentional deaths. Such deaths represent about half of all of the pedestrian fatalities. Trains are the method chosen in $4 \%$ of all completed suicides in Chicago. This is a much higher proportion than in national statistics where the proportion is less than $1 \%$. Explanations for the difference include the dense rail network in Chicago and the much lower involvement of firearms (used in 33\% of suicides in Chicago versus 52\% nationally).

Engineering solutions are most likely less effective for mitigating intentional deaths as the spatial analysis finds that apparent intentional deaths are not strongly related to the density of public access points suggesting that those intending self-harm will seek out a point of access. 
Perhaps not surprisingly intentional deaths are also more prevalent where there is a higher train frequency and a greater proportion of passenger trains that run to a published schedule. Consequently, any countermeasures such as the posting of suicide "hot line" numbers should be concentrated on these lines. Incidents occur disproportionately in the late afternoon hours and on Fridays. However, unlike the experience on subway lines and in Europe, only about a quarter of intentional deaths occur at or near a station. Given that most stations are not staffed, special training of platform staff to identify people in distress ("gatekeeper training") would seem to be less effective in a North American railroad context.

The Chicago data also suggests that intentional deaths are more prevalent in municipalities with higher incomes and lower population density. However, one should not be left with the impression that suicide by train is solely confined to upper-income municipalities. Of the four most notorious hotspots in the Chicago region, two are located in very affluent communities but the other two are in more modest-income suburban communities.

Most of the apparent intentional deaths (at least 70\%) are not associated with any copycat incidents that are proximate to them in time or geography. However, there are some potential local clusters with multiple deaths within a short period of time. Some of these clusters are highly statistically unlikely to have occurred due to pure chance. Presuming that the initiating intentional death in a cluster is a purely random occurrence, at most one in six of all intentional deaths may be due to imitative behavior. There is some evidence that person aged 21 and younger are disproportionately, but not exclusively, involved in these multiple fatality clusters. There was also a highly-publicized suicide that led to a 95\% increase in apparent intentional deaths throughout the region in the 18 weeks following the incident.

The potential for contagion reinforces previous research findings that the authorities and the media need to be sensitive in discussing incidents. As previously mentioned the Chicago media are sensitive to this issue. However, because commuter trains are disproportionately involved, some publicity is unavoidable as information on commuting delays (due to what is referred to euphemistically as a "pedestrian incident") is common knowledge. It also presents something of a conundrum to authorities in deciding how to fashion public service announcements without unduly publicizing trains as a method of suicide. There is an inherent problem that the public information message that is used to discourage unintentional deaths ("trains are fast, cannot stop quickly, and the outcome of a collision is usually fatal") can create a ideation of suicide by train for those in distress, and in Chicago apparent intentional deaths represent half of the pedestrian deaths.

\section{ACKNOWLEDGMENTS}

This work grew out of a suggestion by Marc Magliari, the Chicago-based media relations officer of Amtrak. The initial work was part of a paper by J. Ken Fuller who received an undergraduate degree in Civil Engineering with a minor in Transportation and Logistics from Northwestern University in June 2011. He is now with the Canadian National Railway Company based in Homewood, Illinois. The fatality dataset used in this paper was compiled by Steve Laffey of the Illinois Commerce Commission. 


\section{REFERENCES}

Andriessen, K., Krysinska, K., 2012. Railway suicide in Belgium 1998-2009: Incidence and prevention. Crisis: The Journal of Crisis Intervention and Suicide Prevention 33(1), 39-45. http://dx.doi.org/10.1027/0227-5910/a000105

Botha, J.L., Elmasu, K.A., Leitzell, P.J., 2010. Suicides on Commuter Rail in California: Possible Patterns - A Case Study. MTI Report 10-05. Mineta Transportation Institute, San José State University.

Botha, J.L., Neighbour, M.K, Kaur, S., 2014. An Approach for Actions to Prevent Suicides on Commuter and Metro Rail Systems in the United States. MTI Report 12-33. Mineta Transportation Institute, San José State University.

Centers for Disease Control and Prevention, 1999. Injuries among railroad trespassers in Georgia, 1990-1996. Mortality and Morbidity Weekly Report 48(25), 537-541.

Children's Memorial Hospital of Chicago Research Center, 2011. Examining Suicides in Illinois, 2005-08. Illinois Violent Death Reporting System, volume 2(2).

Federal Railroad Administration, 2013. Rail Trespasser Fatalities: Demographic and Behavioral Profiles. U.S. Department of Transportation.

Fitzpatrick, K. et al (2015). Guidebook on Pedestrian Crossings of Public Transit Rail Services. Transit Cooperative Research Program Report 175. Transportation Research Board, Washington, DC.

Freeman, J., Rakotonirainy, A., Stefanova, T., McMaster, M., 2013. Understanding pedestrian behaviour at railway level crossings: is there a need for more research? Road and Transport Research 22(3), 72-82.

Gabree, S., Chase, S., Doucette, A., Coplen, M, 2014. Potential countermeasures to mitigate suicides on the railroad right-of-way. 2014 Global Level Crossing Safety and Trespass Prevention Symposium, University of Illinois at Urbana-Champaign, August 2014.

George, B.F., 2008. Rail Trespasser Fatalities: Developing Demographic Profiles. Report to the Federal Railroad Administration. Cadle Creek Consulting, Edgewater, MD.

Harrison, J., DaSilva, M., 2013. 2012 Right-of-Way Fatality and Trespass Prevention Workshop. Report DOT/FRA/ORD-13/18. Federal Railroad Administration, U.S. Department of Transportation.

Havârneanu G.M., Burkhardt ,J.M., Paran, F., 2015. A systematic review of the literature on safety measures to prevent railway suicides and trespassing accidents. Accident Analysis and Prevention 81, 30-50. http://dx.doi.org/10.1016/j.aap.2015.04.012 
Hedlund, J., 2000. Risky business: Safety regulations, risk compensation, and individual behavior. Injury Prevention 6(2), 82-89. http://dx.doi.org/10.1136/ip.6.2.82

Kunrath, S., Baumert, J., Ladwig, K-H., 2011. Increasing railway suicide acts after media coverage of a fatal railway accident? An ecological study of 747 suicidal acts. Journal of Epidemiology and Community Health 65(9), 825-828.

http://dx.doi.org/10.1136/jech.2009.098293

Krysinska, K., De Leo D., 2008. Suicide on railway networks: Epidemiology, risk factors and prevention. Australian and New Zealand Journal of Psychiatry 42(9), 763-771.

http://dx.doi.org/10.1080/00048670802277255

Ladwig, K. H., Kunrath, S., Lukaschek, K., Baumert, J., 2012. The railway suicide death of a famous German football player: Impact on the subsequent frequency of railway suicide acts in Germany. Journal of Affective Disorders 136(1), 194-198.

http://dx.doi.org/10.1016/j.jad.2011.09.044

Lloyd's Rail Register, 2007. Study of Pedestrian Behaviour at Public Railway Crossings. Victoria, Australia: Public Transport Safety Victoria.

Lobb, B., 2006. Trespassing on the tracks: A review of railway pedestrian safety research. Journal of Safety Research 37(4), 359-365. http://dx.doi.org/10.1016/j.jsr.2006.04.005

Martino, M., Doucette, A., Chase, S., Gabree, S., 2013. Defining Characteristics of Intentional Fatalities on Railway Rights-of-Way in the United States, 2007-2010. Report DOT/FRA/ORD13/25. Federal Railroad Administration, U.S. Department of Transportation.

Martino, M., Gabree, S., Chase, S., 2013. Demographic Profile of Intentional Fatalities on Railroad Rights-of-Way in the United States. Research Report 13-36. Federal Railroad Administration, U.S. Department of Transportation.

Metaxatos, P., Sriraj, P.S., 2013. Pedestrian/Bicyclist Warning Devices and Signs at HighwayRail and Pathway-Rail Grade Crossings. Report FHWA-ICT-13-013. Illinois Center for Transportation Studies, University of Illinois at Chicago.

Mishara, B.L., 2007. Railway and metro suicides: Understanding the problem and prevention potential. Crisis: The Journal of Crisis Intervention and Suicide Prevention 28(Suppl 1), 36-43. http://dx.doi.org/10.1027/0227-5910.28.S1.36

Mok, S., Savage, I. 2005. Why has safety improved at rail-highway grade crossings? Risk Analysis 25(4), 867-881. http://dx.doi.org/10.1111/j.1539-6924.2005.00642.x

Pelletier, A., 1997. Deaths among railroad trespassers: The role of alcohol in fatal injuries. Journal of the American Medical Association 277(13), 1064-1066.

http://dx.doi.org/10.1001/jama.1997.03540370054036 
Ovenstone, I., 1973. A psychiatric approach to the diagnosis of suicide and its effect upon the Edinburgh statistics. British Journal of Psychiatry 123(572), 15-21.

http://dx.doi.org/10.1192/bjp.123.1.15

Ratnayake, R., Links, P.S., Eynan, R., 2007. Suicidal behaviour on subway systems: A review of the epidemiology. Journal of Urban Health 84(6), 766-781.

http://dx.doi.org/10.1007/s11524-007-9211-5

RESTRAIL (Reduction of Suicides and Trespass on Railway Property) Consortium, 2014. How to Prevent Suicide and Trespass on the Railways and Mitigate the Consequences? A Practical Guide. International Union of Railways (UIC), Paris, France.

http://www.restrail.eu/IMG/pdf/restrail_book.pdf

Reynders, A., Scheerder, G., van Audenhove, C., 2011. The reliability of suicide rates: An analysis of railway suicides from two sources in fifteen European countries. Journal of Affective Disorders 131(1), 120-127.

http://dx.doi.org/10.1016/j.jad.2010.11.003

Savage, I., 2006. Does public education improve rail-highway crossing safety? Accident Analysis and Prevention 38(2), 310-316. http://dx.doi.org/10.1016/j.aap.2005.10.001

Savage, I., 2007. Trespassing on the railroad. Research in Transportation Economics 20(1), 199-224. http://dx.doi.org/10.1016/S0739-8859(07)20008-3

Savage, I., 2013. Comparing the fatality risks in United States transportation across modes and over time. Research in Transportation Economics: The Economics of Transportation Safety 43(1), 9-22. http://dx.doi.org/10.1016/j.retrec.2012.12.011

Silla, A., Luoma, J., 2011. Effect of three countermeasures against the illegal crossing of railway tracks. Accident Analysis and Prevention 43(3), 1089-1094.

http://dx.doi.org/10.1016/j.aap.2010.12.017

Silla, A., Luoma, J., 2012. Main characteristics of train-pedestrian fatalities on Finnish railroads. Accident Analysis and Prevention 45, 61-66. http://dx.doi.org/10.1016/j.aap.2011.11.008

Sonneck, G., Etzersdorfer, E., \& Nagel-Kuess, S., 1994. Imitative suicide on the Viennese subway. Social Science and Medicine 38(3), 453- 457.

http://dx.doi.org/10.1016/0277-9536(94)90447-2

Sung, J.C., Shults, R.A., Bhat, G.L., 2015. Socio-demographic, alcohol use, and other toxicologic characteristics of train suicides in 16 states: Results from the National Violent Death Reporting System (NVDRS), 2005 to 2011. Transportation Research Board, 94 ${ }^{\text {th }}$ Annual Meeting, Washington, DC., January 2015. 
Uittenbogaard A., Ceccato V., 2015. Temporal and spatial patterns of suicides in Stockholm's subway stations. Accident Analysis and Prevention 81, 96-106.

http://dx.doi.org/10.1016/j.aap.2015.03.043 